\title{
La figura del mercader en El anzuelo de Fenisa, de Lope de Vega
}

\section{The figure of the merchant in Fenisa's Hook by Lope de Vega}

\section{ENRICO DI PASTENA}

Dipartimento di Filologia, Letteratura e Lingüística

Università di Pisa

Piazza Torricelli, 2

56126 Pisa. Italia

enrico.dipastena@unipi.it

Orcid ID 0000-0002-7313-7759

Resumen: En la amplia producción teatral de Lope de Vega, no recurren a menudo los mercaderes. Cuando lo hacen, no suelen ser protagonistas ni tener una connotación positiva. Son excepciones a todo ello El anzuelo de Fenisa y Virtud, pobreza y mujer, ambas piezas de derivación italiana. El artículo lleva a cabo una detallada comparación entre la novella décima de la jornada octava del Decamerón y El anzuelo de Fenisa. En su comedia Lope conserva la estructura de conjunto de la novella y sus elementos principales, pero también introduce innovaciones estructurales, como una segunda acción, y sobre todo acaba neutralizando las implicaciones de dinamización social que, más generalmente, el mercader tenía en el Decamerón. En El anzuelo de Fenisa, a través de la figura de Lucindo, la oposición estamental entre la mediana nobleza urbana y el mundo de los comerciantes se elude.

Palabras clave: Lope de Vega, Boccaccio, El anzuelo de Fenisa, Decamerón, mercader.
RECIBIDO: 9 DE MAYO DE 2017 ACEPTADO: 17 DE MAYO DE 2017

\begin{abstract}
In Lope de Vega's extensive theatrical production, merchants do not often appear. When they do, they are not usually protagonists nor have a positive connotation. Exceptions to this are two plays of Italian sources, El anzuelo de Fenisa (Fenisa's Hook) and Virtud, pobreza y mujer (Virtue, poverty and woman). The article carries out a detailed comparison between the tenth novella of the eighth day of the Decameron and El anzuelo de Fenisa. In his comedy Lope retains the overall structure of the novella and its main elements, but he also introduces structural innovations, such as a second plot line, and above all ends up neutralizing the implications of social dynamization that the merchant had more widely in the Decameron. In El anzuelo de Fenisa, through the character of Lucindo, the social strata opposition between the urban middle nobility and the world of merchants is avoided.
\end{abstract}

Keywords: Lope de Vega, Boccaccio, Fenisa's Hook, The Decameron, merchant. 


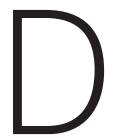

e Lope de Vega bien podría decirse lo que Borges (44) escribió de Quevedo: "es menos un hombre que una dilatada y compleja literatura". En el maremágnum que es el teatro del Fénix, navegable solo distinguiendo corrientes y épocas, no desempeñan un papel destacado los mercaderes o los comerciantes: es cierto, una somera búsqueda en la base de datos ARTELOPE arroja el resultado de casi treinta obras donde interviene esta figura o alguien disfrazado de ella, pero si la búsqueda se realiza teniendo en cuenta las piezas en que se manifiesta con una mínima consistencia "el universo social" correspondiente, los resultados se reducen a la mitad; ${ }^{1}$ y se pierde otra mitad si prescindimos de las comedias en que los mercaderes solo son comparsas; en alguna otra pieza asoman indianos enriquecidos, mientras que cabe observar que lo que se capta más ampliamente son los efectos, ahora dinamizadores, ahora perturbadores, que el dinero va ejerciendo en la sociedad del siglo XVII. ${ }^{2}$

Guiados por la mera intención de ofrecer algunos ejemplos de mercaderes o menciones de su figura extraídos del corpus teatral lopesco, podemos recordar al mercader Octavio, que pretende inflexiblemente cobrar su deuda en El sembrar en buena tierra, comedia urbana de $1616 ;^{3}$ a un mercader de ropa que en Pobreza no es vileza (499) no acepta la venta bajo palabra; y a otro, el mercader milanés de Las flores de don fuan (comedia pulcramente editada hace pocos años por Luis Sánchez Laílla), que en cambio sí fía al protagonista, un segundón rico en virtudes y escaso en medios (vv. 2095-180); una idealización, en el caso concreto, en la que se ha querido ver una nostalgia de tiempos pasados, cuando se estimaba más la virtud que el interés (si la preocupación se repite en Lope, mucho más significativo se ha considerado el hecho de que el autor la refiera a un mercader: Campbell 1996, 114). A veces la figura relacionada con el mundo de los negocios es la que se lleva la peor parte: en Servir a señor discreto, comedia urbana de probablemente 1610-1612, el viejo Silvestre, comerciante rico, es suplantado por don Pedro, hidalgo sin fortuna, en la conquista de la mano de la bella Leonor. Hay casos en que el mercader solo es evocado como si fuera una pesadilla: en Las mudanzas de fortuna y

1. Última consulta: 10 de abril de 2017.

2. Sobre el indiano, ver Campbell (2001), quien señala casos en que también esta figura tiene connotaciones menos negativas de las acostumbradas, y Campbell (1992); ver también Martínez Tolentino. En relación al dinero, ver Campbell (1998), Roncero, y en general Pedraza, González Cañal y Marcello, eds.

3. El coprotagonista Don Félix lo define "cobrador fiero", vv. 1680-81. "DON FÉLIX Tres mil reales / que Octavio me prestó, cobrador fiero". 
sucesos de don Beltrán de Aragón -texto ambientado en la Edad Media (probablemente compuesto hacia 1604-1607) que se ha adscrito ahora a la comedia palatina, ahora a la de privanza, ahora al drama historial- se menciona a un mercader (vv. 451-90) que amenaza con hacer detener al coprotagonista don Juan de Abarca, noble pero pobre, por no poderle devolver este una cantidad, quinientos ducados, que el otro le había prestado (la nota del mercader Dionís Tolosa aparece tras el v. 830): el mercader se reduce así a uno de los obstáculos que ha de sortear el galán enamorado. Finalmente, no olvidemos los personajes que fingen ser negociantes: en el acto primero de El Arenal de Sevilla (vv. 305-88; la comedia es de 1603) vemos cómo dos moros de galera estafan a un desgraciado forastero, venido de Castilla, al que supuestamente venden unas medias que son, en realidad, "trapos y papeles", usurpando un papel que no le corresponde mediante una estafa que no debía ser infrecuente. En el tercer acto de La doncella Teodor (pieza escrita hacia 1608-1610), Leonardo llega a Orán, junto al viejo Foresto, en "hábito de mercaderes" en busca de su hija prisionera de moros (vv. 2317-50; y un auténtico mercader, Finardo, salva a la protagonista: vv. 2351-72). Y sin duda todos tenemos en la memoria a Tristán disfrazado, en El perro del hortelano, de "armenio, con un turbante", es decir, 'de mercader griego' (tras el v. 2754), acompañado por Furio vestido de la misma guisa. Las figuras que hemos mencionado tienen una aparición más o menos fugaz, si es que aparecen; lo mismo le pasa a Tristán con la máscara de mercader (otra cosa es que desempeñe una función clave en el desenlace de la comedia protagonizada por Diana y Teodoro).

Robert Jammes, en un estudio clásico sobre la producción literaria de Góngora, ya hace años observó cómo el público de los corrales solía divertirse, entre otras figuras, a costa del mercader (417), relegado a papeles accesorios o desagradables (el estudioso francés habló de mercaderes concebidos "para atraer la antipatía": 416), con una llamativa excepción en el marco de las comedias lopescas: Virtud, pobreza y mujer. En años más recientes también Ysla Campbell (1996), que ha propuesto una interesante visión panorámica del tema de la mercadería en Lope, antes de examinar con más detenimiento el auto Los acreedores del hombre, ha señalado cierto protagonismo de Hipólito, el mercader indiano de Virtud, pobreza y mujer, figura cuya actuación permite el desenlace feliz, o del Lucindo de El anzuelo de Fenisa, ambos calificados oportunamente por la estudiosa como personajes positivos. Campbell considera que, en la mayoría de los casos, cuando en la producción de Lope la imagen del mercader resulta negativa, su presencia es accesoria y se rela- 
ciona con el comercio menudo, mientras que el comerciante es valorado de forma positiva cuando tiene protagonismo y en las ocasiones en que el dramaturgo se refiere principalmente a "grandes burgueses, aunque no excluye al tendero". Esa duplicidad en la figuración del mercader mostraría, según la investigadora, que el enfoque que se deparaba al mundo de la mercancía era una cuestión aún no del todo resuelta en la época del Fénix (compartimos ese punto de vista por lo que se refiere al trasfondo histórico-ideológico) y que aspectos como la valoración de la virtud, la realización de matrimonios mixtos (el caso del galán indiano protagonista de La noche de San fuan que se casa con una dama noble), la trasformación de burlado a burlador, "significarían -escribe Campbell $(1996,115)$ - una reivindicación de las actividades mercantiles que se inscribe en una preocupación generalizada entre los pensadores reformistas del XVII por restituir una actividad económica en decadencia”. Además, Campbell añade que en el corpus teatral lopesco la relevancia del ámbito de los negocios se aprecia también en explícitas consideraciones sobre la importancia de las operaciones comerciales (así, por ejemplo, en El Arenal de Sevilla) y en la penetración del vocabulario económico-comercial en otras áreas de la vida, como son las alusiones de carácter sentimental o religioso. Lo primero (las consideraciones sobre la relevancia del comercio) quizás sea en Lope más circunscrito y coyuntural; lo segundo (el empleo de un lenguaje permeado de términos económicos) es irrebatible, y de ello tenemos ejemplos en varios géneros literarios, ya desde el siglo XVI. ${ }^{4}$ Ahí están para demostrarlo los trabajos de José Antonio Maravall (1972, 1987 y 1990) sobre la historia del pensamiento político-social en España y las repercusiones que la economía dineraria manifestó en el cosmos teatral y picaresco, así como, más en concreto, el peso que adquiere el sustrato económico, tanto en lo negativo como en su potencial pars construens, en una novela clave como fue el Guzmán de Alfarache, según han ido precisando los bien informados estudios de Michel Cavillac. ${ }^{5}$ También cabe recordar que al filo del Seiscientos la esperanza de una regeneración económica de España cuaja en un ideal de mercader honrado con el que se afirman las potencialidades de una mentalidad mercantil activa y se intenta sustraer a esa figura pública a la opinión común y fundamentalmente negativa con que se la presentaba o satirizaba, ${ }^{6}$ achacándole los rasgos

4. El léxico económico impregna incluso la predicación y no se percibe ruptura entre homo religiosus y bomo oeconomicus (Cavillac 407).

5. Especialmente su Pícaros y mercaderes en el "Guzmán de Alfarache" (1994 en la versión española).

6. Para Cavillac (369) el mercader "honorable" se encarna en el "fabricador de paños" o en el 
de un usurero despiadado, o confiriéndole los paños del extranjero, o de un ser codicioso, hereje o venido a España para sacarle la linfa vital al país. Que esta percepción crítica sea persistente, por otro lado, lo demuestran, solo por ofrecer algunos ejemplos, numerosos textos satíricos o, más específicamente, el propio Guzmán en la treta que arma en Milán, donde estafa a un mohatrero aprovechando la pésima fama de este entre sus conciudadanos (Guzmán de Alfarache, $2^{\mathrm{a}}$ parte, II, caps. 5-6, 228-55), antes de convertirse él mismo en usurero durante su etapa madrileña.

En cualquier caso, volviendo a la "reivindicación de las actividades mercantiles" que se ha querido ver en piezas como El anzuelo de Fenisa o en Virtud, pobreza y mujer, creo que cabe matizarla con decisión. Resulta problemático trazar conclusiones definitivas en un contexto tan amplio e huidizo como el universo dramático de Lope, y antes de llegar a afirmaciones concluyentes es provechoso considerar el género de las piezas, su cronología de redacción y las relaciones que tienen con posibles modelos. No deja de ser revelador que las comedias lopescas donde el mercader desempeña un papel realmente destacado y, en resumidas cuentas, positivo, tengan modelos italianos: $\mathrm{El} \mathrm{an-}$ zuelo de Fenisa (de hacia 1604-1606) se fundamenta en la novella décima de la jornada octava del Decamerón; Virtud, pobreza y mujer (de hacia 1612-1615, probablemente de este último año) descansa sobre la novella trigésimo novena de $\mathrm{Il}$ novellino de Masuccio Salernitano (459-65), ${ }^{7}$ aunque recientemente no se ha descartado que Lope haya imitado un relato del segundo libro de $L a$ piacevol notte, et lieto giorno (1574, ff. 129-131v) de Niccolao Granucci, ${ }^{8}$ quien se inspiró directamente en Masuccio (Di Francia, II, 117), introduciendo sin embargo un desenlace feliz, tal como ocurre en la comedia.

En realidad, El anzuelo de Fenisa, de raigambre picaresca, y Virtud, pobreza y mujer, comedia urbana con elementos de espacialidad exótica y ribetes novelescos, ${ }^{9}$ son rarae aves en el teatro español no solo de Lope (McGrady 2003, 301), con excepciones conocidas, y vinculadas entre ellas, como -para

"mercader en grueso", con variedad en el tipo de tratos realizados y alcance internacional de sus actividades.

7. Defiende la imitación lopesca de Masuccio, negando la influencia de Granucci, McGrady (2003, 300-2, y 2010, 7-11); más recientemente, en la misma línea se encuentra Berruezo Sánchez (200-3).

8. La princeps se puede consultar en línea en: <archivehttps://archive.org/details/imageGXIII316NarrativaOpal>. La hipótesis de la influencia de Granucci se encuentra en Fernández Rodríguez (273). Le agradezco al autor el haberme permitido la consulta de su tesis doctoral.

9. Ver ahora Antonucci (155). Anteriormente, ver el análisis de la comedia por Case. 
limitarnos a ejemplos relevantes- El mercader amante de Gaspar Aguilar y Las firmezas de Isabela de Luis de Góngora: ${ }^{10}$ la primera obra fue una de las fuentes de la segunda y esta última, a su vez, oportunamente se ha relacionado en más de un aspecto con Virtud, pobreza y mujer. ${ }^{11}$ Me voy a ceñir aquí a El anzuelo de Fenisa, que, por un lado, conecta con las comedias que aprovechan para su trama central un relato procedente del Decamerón y, por otro, se relaciona con un grupo de piezas, de ambiente italiano y rufianesco, que revelan el ascendiente de La Celestina.

Nuestra pieza ha sido adscrita con acierto por Joan Oleza al reducido subgénero de las comedias de pícaro o comedias picarescas, ${ }^{12}$ que comienza a definirse como tal probablemente hacia 1596 (la cronología sigue siendo algo borrosa), es decir, entre unos 8 y 10 años antes de que Lope escribiera El anzuelo de Fenisa. Las comedias de este grupo se caracterizan por la presencia de personajes de nivel medio, junto a otros colindantes con el hampa, y por motivos apicarados. Son piezas impregnadas de rasgos de costumbrismo urbano y marcadas por argumentos que implican cierta libertad crítica y moral por parte del dramaturgo; obras chispeantes y divertidas, desarrolladas en una Italia poblada por unos españoles con frecuencia satirizados como fanfarrones.

Serían las artes de mal vivir de Fenisa -y una tradición que además de La Celestina contaba con las comedias "a noticia" de Torres Naharro- las que arrastrarían una serie de figuras y situaciones que hacen de complemento a la trama principal de El anzuelo de Fenisa, cuya armazón, cabe insistir en ello, Lope extrae de Boccaccio. La novella del certaldés (cuyo epígrafe reza: "Una ciciliana maestrevolmente toglie a un mercatante ciò che in Palermo ha portato; il quale, sembiante faccendo d'esservi tornato con molta più mercatantia che prima, da lei accattati denari, le lascia acqua e capecchio") relata las vivencias del joven mercader florentino Niccolò da Cignano, llamado Salabaetto, y de la cortesana madama Iancofiore, de cómo ella lo regala y yace con él, con el fin de engatusarle y robarle el dinero, y de cómo él acaba desquitándose para dejarla finalmente burlada.

10. A estas comedias se puede añadir El mercader de Toledo, de autoría desconocida, aunque haya sido atribuida apócrifamente a Calderón.

11. Ver McGrady (2003), con las correspondientes indicaciones bibliográficas; y antes, al menos Dolfi (1983, I, 277-90) y Dolfi (1994), sobre los contactos entre la pieza gongorina y la comedia de Ariosto I suppositi.

12. Ver Oleza (1991 y 2001). 
Es un cuento bien conocido y no me voy a demorar en él. Me limitaré a recordar que el expediente con que Salabaetto engaña a su vez a la engañadora y recupera sus quinientos florines de oro, haciéndose con otros mil, era popular: en Boccaccio, Salabaetto le deja a la mujer barbera (así llamada por pelar a los incautos) "acqua e capecchio", es decir "agua y estopa”; ${ }^{13}$ Lope mantendrá las pipas llenas de agua en lugar de aceite y sustituirá la borra con cajas vacías, pues solo una de ellas contiene "seis varas de paño encima", según dice un verso de la comedia (v. 3141). El dramaturgo por lo tanto se hace eco del cebo, unos presuntos odres de aceite, con el que el mercader llevará a cabo la contraburla; como recuerda Vittore Branca en su edición del Decamerón, el estratagema de Salabaetto, de ascendencia folklórica, se encuentra con variaciones en múltiples relatos. ${ }^{14}$ Sin embargo, y es un aspecto importante, aparte de los rasgos esenciales de aquel estratagema, nada más en las narraciones precedentes se anticipa a la novella boccacciana, que es reflejo, aquí como en otros cuentos, del conocimiento directo que su autor tenía de los ambientes mercantiles, ampliamente celebrados en esa "epopeya de los mercaderes" que es el Decamerón ${ }^{15}$ proyección de una burguesía emprendedora y dinámica -como la de la familia Bardi y de sus aliados Peruzzi y Acciaiuoli- que se mide con las fuerzas que parecen dominar al hombre (la Fortuna, el Amor, el Ingenio); una burguesía que a través de los Médicis acabará imponiéndose en Florencia también como modelo sociocultural y político. Se entiende muy bien que, en el cuento de Salabaetto y Iancofiore -un cuento que además culmina las tres jornadas (la sexta, la séptima y la octava) que conforman el tríptico del ingenio en el Decamerón - al final salga airosa la astucia mercantil.

A su vez Lope, en la comedia, hace que el mercader valenciano Lucindo, que desembarca en Palermo para vender paños, sea, primero, objeto de las lisonjas y de los dones de la cortesana Lucinda y luego, víctima de su engaño. Tras haberlo halagado y haberse conducido de forma liberal y aparentemente desinteresada para superar la inicial suspicacia del hombre, Fenisa consigue

13. Estopa, es decir, la 'parte basta o gruesa del lino o del cáñamo'. Usamos la versión española del Decamerón de María Hernández Esteban (952). Sobre la posible existencia real en el año 1305 de una palermitana llamada Biancofiore, ver Trasselli (1955).

14. Decameron, II, 1008, n. 1; entre estos relatos, destaca la Disciplina clericalis de Pedro Alfonso (cuento núm. 16).

15. "L'epopea dei mercatanti" es el título de un capítulo de un estudio clásico de Branca (1990, 134-64, con útiles indicaciones bibliográficas; ver también sobre Salabaetto, 172 y 180). Más recientemente, Cherubini (2014) ha ofrecido un breve panorama, desde el punto de vista del historiador, de los grupos sociales presentes en el Decamerón. 
de Lucindo dos mil ducados, al fingir que los necesita para salvar la vida de un hermano que corre el riesgo de ser ajusticiado en otra ciudad siciliana. Solo en el tercer acto llegará el desquite del comerciante, que se vale de falsas mercancías para despertar la codicia de la mujer, lo que le permitirá derrotarla con sus mismas armas y recuperar con creces su dinero. El fracaso de Fenisa será total, pues también la trama amorosa la verá sucumbir.

La nómina de las comedias de Lope que derivan, directa o indirectamente, completa o parcialmente, de cuentos de Boccaccio se ha ido extendiendo sobre todo en el último cuarto de siglo hasta una veintena de obras, ${ }^{16}$ después de que Caroline B. Bourland, en una pionera monografía de principios del siglo XX, señalara la influencia del certaldés en ocho piezas del dramaturgo madrileño, y después de que otros estudiosos durante décadas se ocuparan en profundizar, desde distintos enfoques, en las relaciones entre el autor del Decamerón y el Fénix, pero sin salirse del corpus delimitado por la hispanista norteamericana y coincidiendo por lo general en que Lope tiende a moralizar a Boccaccio. ${ }^{17}$ Algunos de estos sólidos trabajos han sido valiosos para el presente estudio de El anzuelo de Fenisa. Lo primero que se nota al leer detenidamente esta comedia es que Lope ha mantenido la estructura de conjunto de la novella y sus elementos principales, tales como la condición de los protagonistas, la ambientación italiana, el esquema del burlador burlado y numerosos detalles (entre ellos, uno de los más destacados son los procedimientos mercantiles de registro de los bienes en puertos y aduanas, en Boccaccio fruto de conocimiento directo). Quizás incluso el título y las imágenes relacionadas semánticamente con el anzuelo procedan de una invención que Lope calca del boccacciano "adescare", ${ }^{18}$ a menudo traducido al español sencillamente con 'seducir' pero que es literalmente 'atraer con el cebo', po-

16. Ver el estado de la cuestión de Muñoz Sánchez (2013b); y anteriormente, del mismo autor (2011 y 2013a).

17. Ver Metford; Arróniz (290-302); Segre; Arce (1978, refiriéndose a la recepción de toda la producción del certaldés; 1981 y luego 1982, con los correspondientes envíos bibliográficos). Y más tarde, con nuevos elementos de discusión que retomaremos, ver D’Antuono, Dixon, Navarro Durán (2001) y Profeti. Estos trabajos también se refieren, a menudo de paso, a $E l$ anzuelo de Fenisa. Dejob se había centrado exclusivamente en los contactos entre esta comedia y el cuento boccacciano en que se inspiró.

18. El pasaje reza: "femmine del corpo bellissime, ma nimiche della onestà [...] questi cotali mercatanti s'ingegnano d'adescare, e di trarre nel loro amore"; cito de la edición de 1587, 459-60, por las razones explicadas más abajo, modernizando grafía y puntuación cuando es oportuno; la novella se encuentra en las pp. 449-68; además, acudo a la canónica edición del Decameron, al cuidado de V. Branca (en un principio: Firenze, Accademia della Crusca, 1976; luego Torino: Einandi, 1980), en la reimpresión de 1992, II, 1008-24. 
see también el significado de 'atraer con engaños' y pudo haber arrastrado el correspondiente "anzuelo"; ya Covarrubias vincula la expresión "picar en el anzuelo" con el ámbito sexual $;{ }^{19}$ y el Diccionario de Autoridades señala el alcance metafórico del vocablo ('atractivo, asechanza'), relacionándolo, entre otros, con un texto tan significativo como La Celestina. ${ }^{20}$

Como sea que fuere, el Fénix no ha dejado de introducir innovaciones en su comedia. La más evidente se refiere a la onomástica de los personajes; la más sustanciosa es de tipo estructural: una segunda acción. En ella caben nuevos personajes y no se ahorran otras, efímeras estocadas satíricas contra los españoles. ${ }^{21}$ No ha faltado quien, en un afán didáctico-expositivo, ha llegado a aislar cuatro diferentes tramas (así, Gómez Canseco, 167): 1) la propiamente boccacciana, en la que actúan el mercader Lucindo y el criado Tristán, a los que Fenisa engaña, siendo por ellos finalmente engañada; 2) la de Albano, enamorado de Fenisa y antes, de Dinarda en Sevilla, donde se ha enfrentado al hermano de esta, Félix; 3) la de la propia Dinarda, que se ha fugado de casa en traje y con identidad masculinos y que al llegar a Palermo en compañía de dos pícaros, Fabio y Bernardo, se hace pasar por el noble Juan de Lara; y finalmente, 4) la del capitán Osorio, antiguo amante y rufián de Fenisa. En realidad, bien se podría hablar de una doble acción, con la primera protagonizada por el mercader y su astuta contrincante, y la segunda que permite a Fenisa albergar expectativas amorosas destinadas a naufragar (al enamorarse ella de don Juan de Lara, ignorando quien se oculta tras su traje), precisa las relaciones hampescas de la protagonista (con respecto a Osorio) y reintroduce al final el instituto del matrimonio, cuando se reúnen en legítimo nudo Albano y Dinarda. Todo ello merece dos consideraciones. La primera: muy probablemente el original boccacciano no era suficiente para asegurar el desarrollo de los tres actos, ${ }^{22}$ y además Lope tenía la necesidad de atraer aquel material a unos ámbitos y unos valores más acordes con los códigos de la Comedia. La segunda: en la arquitectura de la pieza la figura central es Fenisa,

19. Tesoro de la lengua castellana, s.v. "anzuelo": "se aplica a los mozos que, engolosinados con la hermosura y gracia de alguna mujer, vienen a perder su libertad y a perderse absolutamente".

20. "PÁRMENo [...] Porque soy cierto que esta doncella ha de ser para él cebo de anzuelo o carne de buitrera, que suelen pagar bien el escote los que a comerla vienen", La Celestina, auto XII, 242.

21. Ver por ejemplo los vv. 1468-72 y 1483-86, afines al desprecio explicitado por Fenisa y Celia en la acción principal (vv. 3019-28).

22. Ya Arce 1981, 371 señaló: "el forzado y forzoso aumento de los personajes, la mayor complejidad de la trama central y la presencia de nuevas intrigas que entrelazan a actores y acciones principales o subsidiarias". 
y no Lucindo, tal como por otro lado refleja su título (un octosílabo pensado quizás para ocultar la procedencia del argumento). ${ }^{23}$

Es sobre todo a través de Fenisa como Lope relaciona la trama del mundillo apicarado a la principal, aunque se le han achacado al dramaturgo inverosimilitudes por la presencia de terceros o huéspedes tan ruidosos como Osorio, o por el hecho de que Félix no reconozca a su hermana Dinarda, auténtico centro de la segunda acción, y lo mismo le pase ante la mujer a su prometido Albano (Dejob 152). Sin embargo, estamos con toda evidencia en presencia de elementos convencionales del marco picaresco y de la tradición de la commedia dell'arte en el primer supuesto, y situaciones consabidas, procedentes del cosmos de la narrativa y del teatro italianos, en el segundo (especialmente el reiterado motivo de la dama disfrazada de hombre). Mucho juego darían uno y otro en la escena, aun a costa de su credibilidad, que resulta criterio poco funcional en este caso.

Cesare Segre ha captado con perspicacia y ha expresado de forma admirablemente sintética las principales líneas de fuerza de la relación entre Boccaccio y Lope, mostrándose consciente de los cambios y de las compensaciones producidos por la transcodificación que supone el paso de una novella a una comedia, declarándose propenso a buscar las propiedades inmanentes al sistema expresivo de los dos autores, pero su mirada es panorámica, no llega a enfocar las peculiaridades internas del sistema Comedia, y en el marco del convencionalismo que reconoce en las actuaciones de los personajes se fija solo en los impulsos idealizadores o inhibidores (Segre 109-10), escapándosele en nuestro caso la carga potencialmente irreverente de determinadas situaciones de la acción y del mismo entorno celestinesco en que esta tiene lugar, incluso cuando sus implicaciones se vean reducidas a un marco eminentemente cómico y socialmente bajo como el que aflora en El anzuelo de Fenisa. ${ }^{24}$

Hay que reconocer que Lope elimina la escena sensual del baño que toman Salabaetto y Iancofiore antes de dirigirse a la alcoba de la cortesana. Cabe recordar que esta situación se conserva también en la versión del Decamerón más radicalmente castigada o arreglada (se habla de "rassettatura" en italiano), llevada a cabo por Leonardo Salviati, y publicada en Venecia en 1582. Es verosímil que, en España, Lope y sus contemporáneos leyeran el Decamerón en las ediciones italianas expurgadas, y especialmente en la del

23. Tal como sugirió Joaquín Arce $(1981,369)$.

24. En relación al trabajo de Segre, ver también las consideraciones de Profeti. 
propio Salviati. ${ }^{25}$ Tampoco en este reajuste la novella que nos interesa sufre alteraciones significativas con respecto a la difundida anteriormente: ${ }^{26}$ en la cuarta edición, impresa en Florencia, por la Stamperia dei Giunti, en 1587, que es la que hemos consultado, la secuencia del baño se puede leer íntegra en la p. 461. En el relato destaca la exasperada sensualidad de la situación, mediante la presencia embriagadora de los perfumes y la exquisitez y elegancia de unos objetos que, con la sucesiva cena, deberían confirmar a Salabaetto en su primera impresión de "que [Iancofiore] fuese una gran señora" (954; más adelante se repite: "debía de ser aquella una gran y rica señora", 957). La secuencia de la sala de baños no se podía llevar a escena por evidentes razones de decoro, pero Lope también evita otra posible opción, la de que nos la relate un personaje. El Fénix prefiere centrarse en otras etapas del proceso gradual con que Fenisa vence la desconfianza inicial de Lucindo. El repetirse de los dones de Iancofiore quizás también despierte la codicia del comerciante; lo cierto es que acalla las posibles dudas derivadas -dice el texto- de lo que "hubiese oído murmurar desfavorablemente" de la vida de la cortesana (957). El hecho es que Salabaetto prácticamente no opone resistencia: es él quien, una vez que Iancofiore le ha puesto los ojos encima -son palabras de Boccaccio-, "comenzó a pasar ante la casa de ella" (954).

En Lope la larga preparación del engaño igualmente se vale de dádivas, prendas y ostentada generosidad (el ofrecimiento de una colación que no se toma, y guantes, medias, pastillas olorosas y hasta cien escudos en el primer acto, vv. 855-925; seis camisas de holanda llegarán en el segundo, vv. 118197), pero ha de sortear principalmente la desconfianza previa del mercader, que además de forastero, es extranjero. El Fénix ha transformado al toscano

25. Fue D'Antuono (espec. 28-29) la primera en intentar dar una respuesta a la cuestión relativa a qué edición o ediciones del Decamerón el dramaturgo pudo tener materialmente acceso; en la misma línea se colocó Dixon (espec. 191), al afirmar que Lope debió conocer y usar la versión de Salviati, la más difundida en Italia, ya que tuvo 14 ediciones, 8 de ellas antes de 1602 (ver también Profeti, 112-13, con la correspondiente bibliografía). Recientemente, Muñoz Sánchez (2013b, 165) no ha descartado la posibilidad de que Lope estuviera familiarizado con las otras dos ediciones censuradas (la de los Diputati, con texto "emendato secondo l'ordine del sacro Concilio di Trento", dirigida por Vincenzo Borghini y publicada en Florencia por Giunti en 1573; y la de Luigi Groto, el "ciego de Adria", realizada en 1579, impresa póstumamente en 1588, y reeditada en 1590 y 1612), especialmente con la primera de ellas. El dramaturgo utilizó los cuentos del certaldés como semillero durante unos veinte años; un período tan largo pudo dar pie a que se valiera de varios ejemplares de distintas versiones del Decamerón, según Muñoz Sánchez (2013b, 165).

26. Como hemos adelantado arriba (n. 18), usamos la 4. ${ }^{a}$ edición de Il Decameron di messer Giovanni Boccacci cittadin fiorentino, di nuovo ristampato, e riscontrato in Firenze con testi antichi, e alla sua vera lezione ridotto dal cavalier Lionardo Salviati, 1587, 449-69. 
Salabaetto en un valenciano, respondiendo a un afán de adaptación a los intereses de su público, manteniendo la ambientación en el puerto franco de $\mathrm{Pa}$ lermo y a la vez refiriéndose a una ciudad, Valencia, de la que había observado personal y directamente la próspera tradición mercantil (ver también Arce 1982, 240). Luis Gómez Canseco (171), editor reciente de la pieza, publicada en la Parte VIII, ha observado que Lope conocía bien las tres ciudades evocadas mediante la procedencia de los personajes españoles de la acción de la comedia, cuando la escribió (Toledo y Sevilla, además de Valencia). ${ }^{27}$

El Lucindo dibujado por el Fénix es un personaje que inicialmente muestra cierta prudencia y sabe de dónde le llega el peligro al mercader, ${ }^{28}$ antes incluso de que lo ponga sobre aviso su criado Tristán: Fenisa todavía no ha echado su anzuelo en la playa del puerto de Palermo cuando Tristán señala que hay que guardarse no de la mujer "perfeta en virtud", sino de la "[perfeta] en amar" (vv. 277-78). Es decir, el riesgo está en el erotismo y sobre todo, lo apreciamos en Fenisa, en la amoralidad con que el dinero y el interés lo contaminan. Enviado por su padre a vender paños y cargar trigo (lo declara en el v. 288), el precavido Lucindo parece dispuesto a evitar toda tentación, a pesar de la corta edad..$^{29}$ La discreción es por lo demás virtud alabada en el auténtico mercader, tal como escribió un miembro catalán del gremio ya hacia mediados del siglo XIV (más exactamente en 1355): "[...] és molt necessari a mercader saviessa e discreció, per ço que sàpia conèxer he veyra molts de frau e angans, que per moltes personas malvades són fets e asagats de fer en mercadaries, he que.s sàpia guardar de aquells" (Gual Camarena 58).

Aunque las asechanzas de las que han de guardarse los mercaderes en sus viajes recurren a lo largo del Decamerón, Lucindo es pues figura mucho más suspicaz que el Niccolò de Boccaccio. Con razón Bourland (141) consideró un acierto que el joven valenciano llegara a convencerse solo gradualmente de la sinceridad, que por supuesto no es tal, de los mimos de Fenisa. Tenemos una prueba tangible del recelo de Lucindo en el hecho de que le confía a Tristán (que lo presiona) bolsa, cadena y joyas antes de visitar a Fenisa en su casa (vv. 503-31), lo que suscita comentarios casi admirados en la cortesana, quien le

27. A partir también de este detalle, con especial atención a una alusión a Toledo, D'Antuono (111-14) se ha demorado en las posibles resonancias autobiográficas de los personajes de Albano y Lucindo.

28. Ver vv. 270-76; y tras las palabras de Tristán, los vv. 290-91.

29. Bien lo vio Dejob (150): "[Lope] ha felicissimamente sviluppato un tratto indicato dal Certaldese: una tal quale prudenza mercantile che nel giovine si mischia all'imprudenza della sua età". 
reconoce al antagonista un "ingenio agudo" y se siente espoleada a desplegar todas sus habilidades para embaucarle. ${ }^{30}$ Se perfila así un duelo entre linces. Recuerdo que ya en el umbral del cuento de Boccaccio, el narrador Dioneo, para encarecer el atractivo de lo que va a decir, observa: "[...] manifesta cosa è tanto più l'arti piacere quanto più sottile artefice è per quelle artificiosamente beffato" (1008; donde "artes" vale 'artimañas', trampas, engaños). ${ }^{31}$

$Y$ sin embargo en el segundo acto veremos a un Lucindo que, bajadas las defensas, queda literalmente atrapado en la red de favores que Fenisa le reserva, aparentemente sin pretender nada a cambio. Arrastrado por los encantos y los artificios de la cortesana, Lucindo cae; y con él, acabará claudicando Tristán, a pesar de ser "hombre de mar". Será en el acto conclusivo donde Lucindo tome su venganza. La cronología interna resulta coherente con una burla elaborada y una contraburla igualmente ingeniosa: cada jornada se concentra en un día, con un intervalo de un mes entre una y otra, para dar tiempo de que hagan presa los ardides de Fenisa y se prepare el chasco con que le responde Lucindo.

En Lope como en Boccaccio el mercader protagonista o coprotagonista de la intriga es figura que aprende de sus errores. Pero además el dramaturgo ha quitado al amigo de Salabaetto (y, en la realidad histórica, de Boccaccio), el sagaz Pietro dello Canigiano (“del Canigiano" en la traducción), la paternidad de la treta con la que el protagonista se venga. En la comedia es Lucindo quien la elabora y la pone en práctica, y el criado Tristán, que se ha mostrado fiel a su amo, le auxilia sin llegar a quitarle protagonismo (a diferencia del homónimo de El perro del hortelano). Para Lucindo la clave del éxito de Fenisa fue haberle sabido "regalar" (vv. 2374-76: "El anzuelo con que pesca / es regalar al que coge, / para que después se arroje”). Él hará lo mismo, echándole un anzuelo irresistible que empuja a la mujer a arriesgar y perder su dinero. Lucindo no solo se impone a la contrincante, sino que sale ganando: perdidos dos mil ducados, consigue tres mil, con un beneficio que también se extiende a Tristán (vv. 2971-72), quien había sido acusado por Fenisa de no haberle entregado el dinero del amo. De esa manera, Lope hace revivir el esquema del burlador burlado, ${ }^{32} \mathrm{y}$, si hiciera falta, subraya la analogía mediante un pa-

30. El anzuelo de Fenisa (vv. 736-37): "pasmar un ingenio agudo / es lo que se ha de estimar".

31. En la versión de Hernández Esteban (952) el pasaje suena así: "es cosa manifiesta que la astucia gusta más cuanto más sutil es el astuto que astutamente es burlado por ésta".

32. De "embaucadora embaucada" y de "pescadora pescada" ha hablado Rosa Navarro Durán (respectivamente 2001, 22; y 2013, 35). 
ralelismo de situación y uno verbal: Lucindo anuncia la consumación de su venganza por carta; una falsa epístola había hecho cerrar el dispositivo de la trampa alrededor del mercader; así resume el asunto, sentenciosa y risiblemente, Tristán: "Mamaste tu mismo engaño, / Circe de enredos autora" (vv. 2979-80), en correspondencia del "Mamola su señoría" pronunciado en su momento por la cortesana (v. 1819).

Antes de hacer algunas consideraciones sobre el mercader lopesco, hablaré brevemente de Fenisa, pues la dialéctica principal de la pieza se establece sin duda entre Lucindo y ella, variante de personaje apicarado (y la tentativa de burla al mercader por parte del pícaro era motivo frecuente). Fenisa es figura en que se sustancia el engaño a modo de ingenioso artificio, en el que participan expectativa crematística, encantos personales y habilidades interpretativas (su treta es un dispositivo a tiempo y bien planificado: adviértase que de su presunto hermano hablan tanto la criada Celia -v. 378- como ella -vv. 417-19- ya en ocasión del primer encuentro, nada casual, con Lucindo en la playa). Personaje seductor, que sabe hacer parecer lo que no es y sacar provecho de ello, se prestaba a una interpretación histriónica por parte de la actriz que la encarnara (la comedia formó parte del repertorio de Baltasar de Pinedo -lo sabemos por un documento, tardío, de 1616- y quizás la encarnara la conocida actriz Juana de Villalba). ${ }^{33}$ Esa virtualidad ha sido recuperada en algunos montajes contemporáneos de la pieza (por ejemplo, el de Pilar Miró, el último por ella dirigido antes de su prematuro fallecimiento, al frente de la Compañía Nacional de Teatro Clásico en Madrid en mayo de 1997: la directora confió el papel de Fenisa a Magüi Mira).

Un aspecto sin duda relevante es que, respondiendo a las exigencias de un texto más articulado, la Fenisa de Lope es más acabada que la de Boccaccio. Sigue siendo ella misma el mar en que hacen naufragio los incautos (el léxico de la pesca, incluido el tema del anzuelo y las alusiones al pez-víctima, otorga unidad al personaje y posibilita repetidas alusiones a la situación central), sigue teniendo el ingenio y el descaro de la criatura del certaldés (Bourland, 141), pero el Fénix le atribuye un pasado (se ha independizado de Osorio), una motivación no exclusivamente económica en el presente (la mueve también el deseo de venganza amorosa, sabe ser generosa con los amigos), ${ }^{34} \mathrm{y}$ la dota de una esperanza de futuro, confiriéndole la debilidad de enamorarse

33. Ver en DICAT las noticias relacionadas con la comedia.

34. Lo señalan, entre otros, Gitlitz, xiii, y sobre todo D'Antuono 115. 
ciegamente, lo que permite al dramaturgo alimentar la trama secundaria y hacer total el fracaso de la mujer. De nuevo, parecería que lo funcional se ha impuesto a lo verosímil en el andamiaje de la trama, puesto que una figura tan avispada cae desastrosamente en la redes del amor. ${ }^{35}$ Pero si el castigo final es doble es porque apunta a la doble presunción de Fenisa: la de creerse superior a los demás en su habilidad de estafadora y la de creerse mujer independiente de los hombres (vv. 139-41: “[...] no es razón que viva / quien nació libre también / de un hombre libre cautiva"). Desde el punto de vista de Lope y de sus espectadores estamos casi ante un caso de justicia poética. ${ }^{36}$

Ya es tiempo de tirar de los hilos de nuestro discurso y sacar algunas conclusiones. También en Lope la figura que acaba imponiéndose es la de un mercader, ahora -y por más señas- un español. Cabe preguntarse si el Fénix podía haber cambiado el oficio de su criatura. Hubiera sido complicado -aunque no imposible- hacerlo sin desquiciar la armazón de la trama y sin alterar las justificaciones básicas de los móviles de los personajes. La revancha de Lucindo se juega en una comedia en la que difícilmente se puede entrever una moraleja o una enseñanza (así lo han percibido varios estudiosos). ${ }^{37}$ Concuerdo con Joan Oleza cuando acerca la comedia al amoralismo de El rufián Castrucho y comparto menos la postura de Rosa Navarro, quien vio un final "moralizante" en la reafirmación del mercader y sobre todo en el hecho de que las tretas de Fenisa la llevarían "a conseguir lo que no debe: el dinero". ${ }^{38}$ En la obra la derrota de quien ha usado medios ilícitos no supone ninguna formulación moral. No hay una conversión, ni siquiera falsa, por parte de Fenisa. No se va más allá de un implícito: "Lo que se siembra, se cosecha". Camilo en el tercer acto pronuncia unas palabras que bien podemos aplicar al caso de Fenisa y Lucindo: "el que agravia no de un muro / ni del lugar más secreto, / aun no ha de vivir seguro / de sí mismo, si es discreto" (vv. 3002-5).

En el tono de entretenimiento de la comedia reconocemos la acostumbrada reafirmación de lo nacional. La veta satírica antiespañola que asoma en algún pasaje cimentado en un bilingüismo amañado queda reabsorbida por la superioridad nacional: en correspondencia con la orientación del público lopesco, esta se manifiesta en la victoria del mercader valenciano sobre la

35. La crítica en tal sentido procede de nuevo de Dejob (152).

36. Así lo sugiere Gitlitz (xiv).

37. Entre ellos, Oleza (1991), Campbell $(1995,158)$ y Gómez Canseco (170).

38. Navarro Durán $(2001,22)$. La misma autora parece matizar su juicio en Navarro Durán (2013, 32). En una línea análoga se sitúa Vázquez Melio (490). 
"libre mujer" de Palermo (según definición de Celia en el v. 116), y también en las victorias de Dinarda, Albano y Osorio, los españoles tachados de "bestias" por Fenisa, que se revelan finalmente más sagaces que ella (Gómez Canseco 172). La ambientación italiana -según dijimos, invariada con respecto a la fuente principal de la comedia- se propone en cambio como espacio propicio para aflojar las ataduras sociales de los personajes y volver más fácilmente aceptables para el público las libertades que se toman ${ }^{39}$ (aquí Lope no parece aprovecharla para ejercer una mayor vehemencia crítica). Es en definitiva un territorio ideal más que idealizado, básicamente literario (Gómez Canseco 171).

Algunos estudiosos han hecho hincapié en la presencia, en la pieza, de un dualismo sociocultural entre mundo aristocrático y mundo mercantil, viéndolo plasmado respectivamente en don Félix, Dinarda y Albano por un lado, y Lucindo y Fenisa por el otro. ${ }^{40}$ Ateniéndonos a la letra del texto y a las situaciones que plantea, y limitándonos al noble que debería restaurar su nombre y al negociante, es decir, respectivamente al don Félix que es miembro de la nobleza urbana sevillana y al mercader valenciano, se diría más bien que Lope haya reducido inicialmente la distancia entre uno y otro para finalmente dejar claro que no existe auténtico antagonismo entre ellos. El dramaturgo sugiere al comienzo de las relaciones de don Félix y Lucindo un paralelismo entre ambos, quienes respectivamente llegan o vuelven a Palermo en busca, cómo no, cada uno de su honor. Félix ha de reestablecer el de su familia a raíz de la conducta de su hermana; Lucindo recuperar su caudal, que para un mercader es mucho más que mero capital, pues es en el peculio donde reside la reputación: para dar a crédito hay que tener crédito, podríamos decir. Así lo manifiesta el joven valenciano a don Félix, cuando este se declara preocupado por su propia honra: "[...] habéis de saber / que en cualquiera mercader / es honra también la hacienda. / Tras el caudal, si se pierde, / va el crédito, pues, perdido" (vv. 2423-27). ${ }^{41}$

También cabe subrayar el vínculo de amistad caballerosa que se establece entre Félix y Lucindo, lo que, más allá de los agasajos formales, les lleva a que

39. Ya Vossler (250) había señalado, refiriéndose a El galán Castrucho, que la ambientación en Italia contribuye a que las situaciones prostibularias resulten menos estridentes para el auditorio.

40. Ver especialmente D'Antuono (114-22); y ver Gitlitz (xii), y Casa (167-70).

41. Y en el segundo acto, antes de entregar a Fenisa el dinero que le pide prestado, Lucindo afirma (vv. 1762-65): "Pero advertid, gloria mía, / que un mercader sin dinero / es como amor sin tercero, / es como sin luz el día”. 
cada uno revele al otro la auténtica finalidad de su viaje (un asesinato que no hará falta perpetrar y una venganza que sí se lleva a cabo). En cambio, evitaría atribuir una importancia excesiva al hecho de que la venganza de Lucindo asuma términos monetarios. No creo que deba verse en ella "una valoración del trabajo mercantil, del esfuerzo, contra el ocio y el parasitismo picarescos" (Campbell 1995, 163-64), como se ha escrito, añadiendo que no es la nobleza el grupo que aporta la solución del problema. La cuestión es que Lucindo se limita a reintegrar el dinero a su bolsa, lo hace pagando con la misma moneda a quien lo había timado y puede así recobrar su credibilidad y estatus. Sencillamente, sale victorioso de un desafío a golpes de astucia.

Además, se lee en la comedia el reconocimiento explícito por parte del mercader de la superioridad de la condición de su interlocutor. De nuevo es Lucindo quien habla, mostrándole gratitud a don Félix por su amistad. Son palabras sumamente reveladoras de la caracterización que Lope hace del mercader en esta pieza: "Habeisme honrado / en no haberme despreciado / por la humildad de mi nombre; / que siendo don Félix vos, / caballero sevillano, / yo mercader valenciano, / tan desiguales los dos, / debo estimar con razón / que me tratéis como amigo" (vv. 2327-35). Se trata de la ratificación de una superioridad estamental. El oficio de mercader lleva implícita una diferenciación social. Economistas y memorialistas la habían lamentado. ${ }^{42} \mathrm{Al}$ menos supuestamente (varios casos testimoniaban en realidad el poder de atracción que para la nobleza titulada ejercía el dinero) ${ }^{43}$ ello seguía siendo una marca de desprestigio ante la nobleza de sangre, por proceder la riqueza de un oficio mecánico y por lo que tenía de mancha la economía dineraria, mancha de la que el mismo Lucindo, por muy ingenioso que se demuestre en el transcurso de la obra, de alguna forma no se siente libre, si hemos de creer en lo que dice. No sería incorrecto por lo tanto afirmar que en El anzuelo de Fenisa a través de la figura de Lucindo la oposición estamental entre la mediana nobleza urbana y el mundo de los comerciantes se elude.

42. El arbitrista Martín González de Cellorigo, en un pasaje muy citado, a principios del siglo XVII -es decir, pocos años antes de que el Fénix compusiese su comedia- escribía: "[...] por las constituciones de las órdenes militares, no puede tener hábito mercader ni tratante: que no parece sino que se han querido reducir estos Reinos, a una república de hombres encantados, que vivan fuera del orden natural" (Memorial de la politica necesaria, y util restauracion á la Republica de España, y estados de ella..., f. 25).

43. Soria Mesa (34-35) considera que la sociedad de la España moderna fue más porosa, abierta y flexible de lo que se ha venido afirmando. Anteriormente, ver el ejemplo de unión matrimonial señalado por Domínguez Ortiz $(1990,491)$ en el marco de su cuadro sobre la condición de pequeños y grandes comerciantes en España durante el siglo XVII. 
Así es como se inscribe el tema mercantil de Boccaccio en el marco de los valores de nuestra comedia y como la sustancia burguesa de la novella entra en relación con la caballería urbana española. Se hace a costa de desvirtuar el mundo de la mercadería de sus alicientes e impulsos socialmente más renovadores y osados, tan bien captados por el certaldés a lo largo del Decamerón, como dijimos, y capaces de producir una subversión de jerarquías y de imponer las virtudes de una burguesía que se ha hecho a sí misma; entre ellas, la prudencia: ¿acaso no le sugiera Lucindo a don Félix una más razonable resolución para tomar su venganza? ${ }^{44}$ En la pieza el mercader seguirá saliéndose con la suya, pero sabiendo que ha de quedar en su lugar (que es lo que históricamente a menudo los mercaderes no hacen, ni siquiera de manera literal); sigue siendo un personaje atractivo pero no está en condición de cambiar la sociedad y mucho menos de llegar a gobernarla. Ni siquiera se lo propone.

Los principales méritos de El anzuelo de Fenisa consisten en el desparpajo de sus protagonistas, en la animación de la acción y de algunos ambientes, en la viveza del lenguaje. Sin embargo, si quisiéramos encontrar figuras de mercaderes dinámicas, modernas y virtualmente innovadoras, deberíamos dirigir nuestras miradas hacia otras obras literarias y otros géneros del Siglo de Oro.

\section{OBRAS CITADAS}

Alemán, Mateo. Guzmán de Alfarache. Ed. José Ma Micó. 2 vols. 7. ed. Madrid: Cátedra, 2006.

Alfonso, Pedro. Disciplina clericalis. Ed. María Jesús Lacarra. Trad. Esperanza Ducay. Zaragoza: Guara, 1980.

Antonucci, Fausta. "Algunos ejemplos de hibridación genérica en el teatro de Lope: reflexiones al hilo de unas búsquedas en la base de datos Artelope". Teatro de palabras 7 (2013): 141-58.

Arce, Joaquín. "Boccaccio nella letteratura castigliana: panorama generale e rassegna bibliografico-critica". Il Boccaccio nelle culture e letterature nazionali, ed. Francesco Mazzoni, Firenze: Olschki, 1978. 63-105.

Arce, Joaquín. "Comedias de Lope basadas en cuentos de Boccaccio". Teoría y realidad en el teatro español del siglo XVII: la influencia italiana. Roma:

44. Ver vv. 2666-68: "Y si habéis de matar por propia espada / ese que os ofendió, deciros quiero / más seguro camino". 
Publicaciones del Instituto Español de Cultura y de Literatura de Roma, 1981. 367-83.

Arce, Joaquín. Literaturas española e italiana frente a frente. Madrid: EspasaCalpe, 1982.

Arróniz, Othón. La influencia italiana en el nacimiento de la comedia española. Madrid: Gredos, 1969.

Artelope: Base de Datos y Argumentos del teatro de Lope de Vega. ARTELOPE. Dir. Joan Oleza, València: Universitat de València. Publicación en web: $<$ http://artelope.uv.es>.

Berruezo Sánchez, Diana. "Il Novellino" de Masuccio Salernitano y su influencia en la literatura española de la Edad de Oro. Vigo: Academia, 2015.

Boccaccio, Giovanni. Decameron. Ed. Vittore Branca. 2 vols. Torino: Einaudi, 1980.

Boccaccio, Giovanni. Decamerón. Ed. y trad. María Hernández Esteban, Madrid: Cátedra, 1994.

Borges, Jorge Luis. "Quevedo". 1952. Obras completas II. Buenos Aires: Emecé, 2002.38-44.

Bourland, Caroline B. "Boccaccio and the Decameron in Castilian and Catalan Literature". Revue Hispanique 12 (1905): 1-233.

Branca, Vittore. Boccaccio medievale e nuovi studi sul "Decameron". 1956. 7. ed. Firenze: Sansoni, 1990.

Campbell, Ysla. "Nostalgia y transgresión en tres comedias de Lope de Vega". Relaciones literarias entre España y América en los siglos XVI y XVII. Ciudad Juárez: Universidad Autónoma de Ciudad Juárez, 1992. 65-87.

Campbell, Ysla. "Picardía y crisis moral en El anzuelo de Fenisa". El escritor y la escena III. Estudios en honor de Francisco Ruiz Ramón. Ed. Ysla Campbell. Ciudad Juárez: Universidad Autónoma de Ciudad Juárez, 1995. 155-64.

Campbell, Ysla. "El comercio y las finanzas en el teatro de Lope de Vega". Teatro, historia y sociedad. (Seminario Internacional sobre Teatro del siglo de Oro Español). Asociación Internacional de Teatro Español y Novobispano del Siglo de Oro. Murcia, octubre 1994. Ed. Carmen Valcárcel Hernández. Murcia/Ciudad Juárez: Universidad de Murcia/Universidad Autónoma de Ciudad Juárez, 1996. 113-22.

Campbell, Ysla. "Conceptos dramáticos de la riqueza. El poder del dinero". Actas del IV Congreso Internacional de la Asociación Internacional Siglo de Oro, Alcalá de Henares, 22-27 de julio de 1996. Eds. María Cruz García de 
Enterría y Alicia Cordón Mesa. Vol. 1. Alcalá: Servicios de Publicaciones de la Universidad de Alcalá, 1998. 309-16.

Campbell, Ysla. "La otra imagen del indiano en algunas comedias de Lope de Vega". Teatro: revista de estudios teatrales 15 (2001). 69-81.

Casa, Frank P. "El mercader, el hidalgo y la dama en El anzuelo de Fenisa". El escritor y la escena III. Estudios en honor de Francisco Ruiz Ramón. Ed. Ysla Campbell. Ciudad Juárez: Universidad Autónoma de Ciudad Juárez, 1995. 165-72.

Case, Thomas E. "Contextuality and intertextuality in Lope's Virtud, pobreza $y$ mujer". Bulletin of the Comediantes 50.2 (1998). 317-30.

Cavillac, Michel. Pícaros y mercaderes en el "Guzmán de Alfarache". Granada: Universidad de Granada, 1994.

Cherubini, Giovanni. "Il Decameron letto dagli storici del Medioevo". Bullettino dell'Istituto Storico per il Medio Evo 116 (2014): 171-91.

Covarrubias Horozco, Sebastián de. Tesoro de la lengua castellana o española. Eds. Ignacio Arellano y Rafael Zafra. Madrid: Iberoamericana/Vervuert, 2006.

D'Antuono, Nancy L. Boccaccio's "Novelle" in the Theater of Lope de Vega. Madrid: Porrúa Turanzas, 1983.

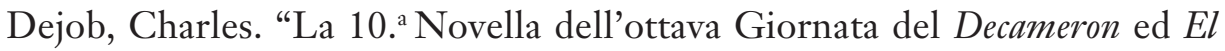
anzuelo de Fenisa di Lope de Vega". Rassegna bibliografica della Letteratura Italiana 1 (1893): 149-52.

Di Francia, Letterio. Novellistica. 2 vols. Milano: Vallardi, 1924-1925.

DICAT: Diccionario biográfico de actores del teatro español. Dir. Teresa Ferrer, Kassel: Reichenberger, 2008.

Dixon, Victor. "Lope de Vega no conocía el Decameron de Boccaccio". El mundo del teatro español en su Siglo de Oro: ensayos dedicados a Fobn E. Varey. Ed. José María Ruano de la Haza. Ottawa: Dovehouse, 1989. 185-96.

Dolfi, Laura. Il teatro di Góngora: "Comedia de las firmezas de Isabela". I - Studio e nota filologica. Pisa: C. Cursi editore \& F./Università degli Studi di Firenze, 1983.

Dolfi, Laura. "Una fuente italiana de Las firmezas de Isabela de Góngora". Hommage à Robert fammes. Vol. 1. Toulouse: Presses Universitaires du Mirail, 1994. 331-42.

Domínguez Ortiz, Antonio. "La sociedad española en el siglo XVII". La crisis

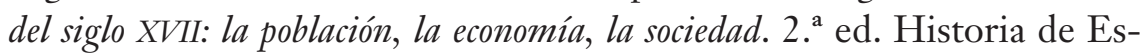
paña Menéndez Pidal 23. Madrid: Espasa-Calpe, 1990. 395-593. 
Fernández Rodríguez, Daniel. Las comedias bizantinas de Lope de Vega: caracterización genérica, tradición y trascendencia. Tesis doctoral, Barcelona: Universidad Autónoma de Barcelona, 2016.

Gitlitz, David M. "Introduction”. El anzuelo de Fenisa: Fenisa's Hook, or Fenisa the Hooker. San Antonio (Texas): Trinity UP, 1988. VII-XXV.

Gómez Canseco, Luis. "Prólogo". Lope de Vega Carpio, El anzuelo de Fenisa. Ed. Luis Gómez Canseco. Comedias de Lope de Vega. Parte VIII. Coord. Rafael Ramos. Vol. 1. Lérida: Milenio-Universitat Autònoma de Barcelona, 2009. 165-81.

González de Cellorigo, Martín. Memorial de la politica necesaria, y util restauracion á la Republica de España, y estados de ella... Valladolid: Iuan de Bostillo, 1600.

Granucci, Niccolao. La piacevol notte, et lieto giorno. Venezia: Vidali, 1574.

Gual Camarena, Miguel, ed. Primer manual hispánico de mercadería (siglo XIV). Barcelona: CSIC, 1981.

Jammes, Robert. La obra poética de don Luis de Góngora y Argote. Madrid: Castalia, 1987.

Maravall, José Antonio. "Economía dineraria y forma política estatal”. Estado moderno y mentalidad social. Siglos XV al XVII. Vol. 2. Madrid: Revista de Occidente, 1972. 57-100.

Maravall, José Antonio. La literatura picaresca desde la historia social (siglos XVI y XVII). Madrid: Taurus, 1987.

Maravall, José Antonio. Teatro y literatura en la sociedad barroca. Ed. Francisco Abad. Ed. corregida y aumentada. Barcelona: Crítica, 1990.

Martínez Tolentino, Jaime. "El indiano en tres comedias de Lope de Vega". Teatro: revista de estudios teatrales 15 (2001): 83-96.

McGrady, Donald. "Lope frente a Góngora: orígenes, relación y sentido de Virtud, pobreza y mujer y Las firmezas de Isabela". Hispanic Review 71.3 (2003): 297-324.

McGrady, Donald. "Prólogo". Lope de Vega Carpio. Virtud, pobreza y mujer. Ed. Donald McGrady. Newark: Juan de la Cuesta, 2010. 7-31.

Metford, John Callan James. "Lope de Vega and Boccaccio's Decameron". Bulletin of Hispanic Studies 29.114 (1952): 75-86.

Muñoz Sánchez, Juan Ramón. "Escribia / después de haber los libros consultado: a propósito de Lope y los novellieri, un estado de la cuestión (con especial atención a la relación con Giovanni Boccaccio). Parte I". Anuario Lope de Vega 17 (2011): 85-106. 
Muñoz Sánchez, Juan Ramón. "Escribía / después de haber los libros consultado: a propósito de Lope y los novellieri, un estado de la cuestión (con especial atención a la relación con Giovanni Boccaccio). Parte II”. Anuario Lope de Vega 19 (2013a): 116-49.

Muñoz Sánchez, Juan Ramón. "Yo be pensado que tienen las novelas los mismos preceptos que las comedias: de Boccaccio a Lope de Vega". Estelas del "Decamerón” en Cervantes y en la literatura del Siglo de Oro. Málaga: Universidad de Málaga, 2013b. 163-86.

Navarro Durán, Rosa. "Lope y sus comedias de enredo con motivos boccaccianos". Insula 658 (2001): 22-24.

Navarro Durán, Rosa. "Caballeros que no lo son y damas que no lo parecen: entra Lope pisando fuerte". La desvergüenza en la comedia española. XXXIV Fornadas de tatro clásico (Almagro, 5, 6 y 7 de julio de 2011). Eds. Felipe B. Pedraza Jiménez, Rafael González Cañal y Elena E. Marcello. [Cuenca]: Universidad de Castilla-La Mancha, 2013. 17-37.

Oleza, Joan. "Las comedias de pícaro de Lope de Vega: una propuesta de subgénero". Comedias y comediantes. Eds. Manel Diago y Teresa Ferrer Valls. València: Universitat de València, 1991. 165-88.

Oleza, Joan. "El primer Lope: un haz de diferencias". Ínsula 658 (2001): 12-14. Pedraza Jiménez, Felipe B., Rafael González Cañal, y Elena E. Marcello, eds. El dinero y la comedia española. XXXVII Fornadas de teatro clásico (Almagro, 10, 11 y 12 de julio de 2014). [Cuenca]: Universidad de Castilla-La Mancha, 2016. Profeti, Maria Grazia. "Il Decamerone in Spagna nei Secoli d'Oro: dai temi alle strutture". Raccontare nel Mediterraneo. Ed. Maria Grazia Profeti. Firenze: Alinea, 2003. 105-26.

Roncero López, Victoriano. "Función del dinero en la estructura social en las comedias de Lope de Vega". El dinero y la comedia española. XXXVII Fornadas de teatro clásico (Almagro, 10, 11 y 12 de julio de 2014). Eds. Felipe B. Pedraza Jiménez, Rafael González Cañal y Elena E. Marcello. [Cuenca]: Universidad de Castilla-La Mancha, 2016. 37-58.

Rojas, Fernando de (y "Antiguo autor"). La Celestina: Tragicomedia de Calisto y Melibea. Eds. Francisco J. Lobera, Guillermo Serés y otros. Barcelona: Crítica, 2000.

Sacchetti, Franco. Il trecentonovelle. Ed. Antonio Lanza. Milano: Sansoni, 1984.

Salernitano, Masuccio. Novellino. Ed. Luigi Settembrini, a c. di Salvatore S. Nigro. Milano: Rizzoli, 1990. 
Salviati, Leonardo. Decameron: Il Decameron di messer Giovanni Boccacci cittadin fiorentino, di nuovo ristampato, e riscontrato in Firenze con testi antichi, e alla sua vera lezione ridotto dal cavalier Lionardo Salviati. Firenze: Stamperia dei Giunti, 1587.

Segre, Cesare. "Da Boccaccio a Lope de Vega: derivazioni e trasformazioni". Semiotica filologica. Torino: Einaudi, 1979. 97-115.

Soria Mesa, Enrique. La nobleza en la España moderna. Cambio y continuidad. Madrid: Marcial Pons, 2007.

Trasselli, Carmine. "Il Decameron come fonte storica". Rassegna di cultura e vita scolastica 9 (1955): 6.

Vázquez Melio, María. "Una tupida red de engaños: las comedias de pícaros de Lope de Vega". "Festina lente". Actas del II Congreso Internacional fóvenes Investigadores Siglo de Oro (FISO 2012). Eds. Carlos Mata Induráin, Adrián J. Sáez y Ana Zúñiga Lacruz. Pamplona: Servicio de Publicaciones de la Universidad de Navarra, 2013. 481-92.

Vega Carpio, Lope de. El anzuelo de Fenisa. Ed. Luis Gómez Canseco. Comedias de Lope de Vega. Parte VIII. Coord. Rafael Ramos. Vol. 1. Lérida: Milenio-Universitat Autònoma de Barcelona, 2009. 163-304.

Vega Carpio, Lope de. El Arenal de Sevilla. Ed. Manuel Cornejo. Comedias de Lope de Vega. Parte XI. Coords. Laura Fernández y Gonzalo Pontón. Vol. 2. Madrid: Gredos, 2012. 459-610.

Vega Carpio, Lope de. La doncella Teodor. Ed. Julián González-Barrera. Comedias de Lope de Vega. Parte IX. Coord. Marco Presotto. Vol. 1. Lérida: Milenio-Universitat Autònoma de Barcelona, 2007. 167-302.

Vega Carpio, Lope de. Las flores de don fuan y rico y pobre trocados. Ed. Luis Sánchez Laílla. Comedias de Lope de Vega. Parte XII. Coord. José Enrique Laplana Gil. Vol. 2. Madrid: Gredos, 2013. 155-336.

Vega Carpio, Lope de. Las mudanzas de fortuna y sucesos de don Beltrán de Aragón. Ed. Gonzalo Pontón. Comedias de Lope de Vega. Parte III. Coord. Luigi Giuliani. Vol. 1. Lérida: Milenio-Universitat Autònoma de Barcelona, 2002. 253-396.

Vega Carpio, Lope de. La noche de San Fuan. Ed. Anita K. Stoll. Kassel: Reichenberger, 1988.

Vega Carpio, Lope de. El perro del hortelano. Ed. Paola Laskaris. Comedias de Lope de Vega. Parte XI. Coords. Laura Fernández y Gonzalo Pontón. Vol. 1. Madrid: Gredos, 2012. 53-262.

Vega Carpio, Lope de. Pobreza no es vileza. En Obras de Lope de Vega publicadas 
por la Real Academia Española. Vol. 12. Madrid: Sucesores de Rivadeneyra, 1901. 477-517.

Vega Carpio, Lope de. El sembrar en buena tierra. Eds. María Morrás y Xavier Tubau. Comedias de Lope de Vega. Parte X. Coords. Ramón Valdés Gázquez y María Morrás. Vol. 2. Lérida: Milenio-Universitat Autònoma de Barcelona, 2010. 1043-180.

Vega Carpio, Lope de. Servir a señor discreto. Ed. José Enrique Laplana Gil. Comedias de Lope de Vega. Parte XI. Coords. Laura Fernández y Gonzalo Pontón. Vol. 1. Madrid: Gredos, 2012. 759-918.

Vega Carpio, Lope de. Virtud, pobreza y mujer. Ed. Donald McGrady. Newark: Juan de la Cuesta, 2010.

Vossler, Karl. Lope de Vega y su tiempo. Trad. Ramón de la Serna. Madrid: Revista de Occidente, 1933. 